\title{
We K03
}

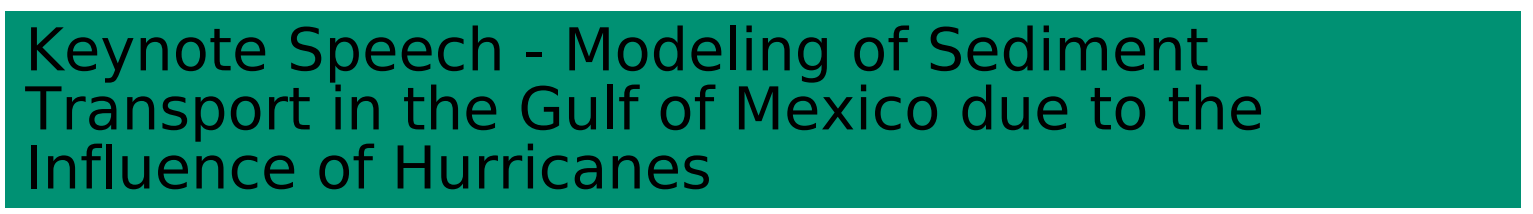

\author{
J.P.M. Syvitski* (University of Colorado-Boulder), H.G. Arango (Rutgers \\ University), C.K. Harris (University of California), E.H. Meiburg (University \\ of California), C.J. Jenkins (University of Colorado-Boulder), E.W.H. Hutton \\ (University of Colorado-Boulder), G. Auad (U.S. Department of the Interior) \\ $\&$ F. Xing (The Water Institute of the Gulf)
}

\section{SUMMARY}

The Mississippi River delivers $96 \%$ of the fluvial sediment flux (480 MT/y) to the Northern Gulf of Mexico. The Northern Gulf of Mexico is characterized by low ocean energy $(0.9 \mathrm{~m}$ average wave heights, low tidal range of $0.3 \mathrm{~m}$ ). During extreme events, wave heights exceed $10 \mathrm{~m}$ in deep water, and near shore waves reach $16 \mathrm{~m}$. Large waves can re-suspend seafloor sediment and liquefy the seafloor, both being viable mechanisms for inducing turbidity currents. The outer continental shelf region is a mature offshore oil and gas production area generating more than 1.7 million of barrels of oil per day, through 3,500+ oil platforms. The northern GOM currently has more than 28,000 miles of underwater pipes. Most of the structural damage to this network is associated with extreme oceanic and atmospheric events. $5 \%$ of the underwater pipes are broken or damaged by sudden and violent cascading of sediments. A shelf-slope modeling workflow is developed to model these rare sediment transport events based on the following models (WBM, WaveWatch III, ROMS, Hurrislip, and RANS-TURBINS). A second modeling workflow is designed to address the near shore environment using Delft3D and SWAN models. Here the focus is on inland propagating storm surge that inundate and erode large sections of the coast. When we compare the rare but extraordinary hurricane events with the more numerous but less severe winter storms, winter storms are seen to be more important from a geological perspective. Discussion will focus on why complex modeling schema is important in solving real world problems. 